\section{THE STUDY OF LIFE.}

The Study of Animal Life. By Prof. J. A. Thomson. Revised edition. Pp. xvi +477 . (London: John Murray, 1917.) Price 6s. net.

" FOR about a quarter of a century this book F ... has had an apparently useful life as an introduction to zoological science." With these words Prof. J. Arthur Thomson begins his short preface, and he is well and handsomely entitled to them. The book is not a large one, but it abounds in information, and the author sets it all forth in an easy way, with the practised skill of an old hand at teaching. The first part contains a few eloquent chapters on such themes as the "Wealth of Life," the "Web of Life," and the "Social and Domestic Life of Animals," and closes with a slighter sketch of the physiological functions and activities of the body; the second part, which is copiously illustrated, deals with structure and classification; the third, in like manner, with embryology; and the fourth and last with the facts and theories of evolution.

The array of facts is remarkable, and not less so is the immense number of recent or current theories which are dealt with or touched on in the book. Lamarck and von Baer, Spencer and Haeckel, Galton, Mendel and De Vries, and a hundred more, all find their place in a brief historic survey; they are all duly honoured, and occasionally criticised-but the book is not written for the sceptic. In writing a chapter on "Vitality" (as Prof. Thomson does not shrink from doing) he calls in a little host of thinkers and philosophers to help him-Huxley and Haeckel, Clifford and Joly, Child and E. S. Russell and Driesch; he leans in the end to views which ine himself has done much to promulgate: "that we require ultra-material, notably historical, concepts for describing organisms. For the organism is a psycho-physical individuality (a mind-body or body-mind) which has enregistered within itself the gains of experience and experiment and has ever its conative bow bent towards the future."

In all popular books, however good they be, even as this one is, there is an inevitable tendency to make use, without more ado, of old familiar elementary statements, which are by no means always sound; just as the classical scholar, for instance, is (or used to be) too apt to take his texts for gospel, and to shirk the weary work of searching manuscripts. There is at least one such case, I think, where Prof. Thomson falls into error-in regard to the very common and familiar subject of the retraction or "sheathing" of a cat's claws; at the same time, if he offends, he does so in good company. His drawing (on p. 35$)$ is a familiar one, closely resembling Mivart's, but it is not accurate; the figure "III.," for the third phalanx, points to the head of the second. But, and this is the important thing, Prof. Thomson explains the mechanism by saying that "the claw is retracted into its sheath-an adaptation for keeping it sharp when the animal is at rest or is simply walking." In like manner, Huxley talks of the claws being "completely retracted within the sheaths of the integument, when the animal does not desire to use them"; and Max Weber speaks of "die in der Haut zurückziehbaren Krallen, wodurch sie scharf bleiben." But the fact is that the "sheath" is very unimportant, if not wholly superfluous, part of the mechanism. Owen and Mivart do not mention it at all. It is a mere ruckle of skin, which neither covers nor protects the sharp point of the claw. John Hunter describes it with perfect accuracy: "The skin which covers the last phalanx is very loose; and when this phalanx is drawn up or back, the skin covers a great deal of the root of the claw." But the really important fact is (as John Hunter was, I think, the first to show) that the last phalanx, claw and all, is crooked up or back, in a state of over-extension; so that the claw is raised off the ground--almost precisely as the hammer in a pianoforte is raised off the string.

D. W. T.

\section{DUR BOOKSHELF.}

The Cancer Problem: A Statistical Study. New edition. By C. E. Green. Pp. ix + I40. (Edinburgh and London: W. Green and Son, Ltd., I9I7.)

IT is well known that the incidence of cancerous diseases varies considerably in different districts and in different occupations. In this book $\mathrm{Mr}$. Green has attempted to find some factor which will explain this difference in incidence, and he has critically examined the local distribution of cancer in different districts, particularly in Scotland, and the conditions which obtain in those districts. He finds that cancerous districts, as a rule, are particularly associated with the burning of coal as fuel, while in the non-cancerous ones wood or peat is the staple fuel. Thus in Nairnshire, which has the highest mortality figure from cancer in Scotland, the cancer deaths for the last ten years are confined to a definite area, while the rest of the county (roo square miles) is entirely free, and in the cancerous area coal is entirely or partially used as fuel, while in the non-cancerous area peat is universally used. The same holds good for other parts of the country. Thus, in the Orkneys, which, as a whole, have a cancer mortality slightly above that for Scotland, Stenness has a cancer death-rate of I out of 42 from all causes and peat is the only fuel, while in Sanday, where coal alone is burned, the cancer death-rate is I out of 9 from all causes. A strange anomaly, however, was met with. In Birsay and in St. Andrews, in the Orkneys, the cancer mortality is practically as great as in Sanday, yet peat only is burned. Investigation showed that the peat used in these two districts is peculiar, being hard and stony and having a high content of sulphur like coal. From these and other facts the author concludes that a high sulphur content of the fuel is NO. 25O4, VOL. IOO] 